\title{
ESTELAS VIRREINALES PARA UNA CONFIGURACIÓN TRANSANDINA LAS LENGUAS DEL IMPERIO EN FRAY MIGUEL DE MONTALVO Y ENRIQUE GARCÉS
}

\author{
POR \\ Vicente Bernaschina SchÜRMANN \\ Europa-Universität Flensburg
}

Puede parecer una perogrullada afirmar que la poesía lírica (como se entiende hoy en la cultura occidental) se inscribe en el Nuevo Mundo a partir de una translatio. Sin embargo, muy pocas veces nos preguntamos qué es lo que significa específicamente esa translatio en el ámbito de la poesía virreinal en la zona andina, cuál es la forma específica que adquiere y qué consecuencias conlleva para las prácticas poéticas en su momento y para aquellas que se conformarán en los siglos a venir. Al hablar de poesía lírica, normalmente damos por sentado que durante los siglos XV y XVI ésta fue producto de una translatio studii (que corre parejas a la translatio imperii, como lo declara Asensio siguiendo a Nebrija) y que, si bien pudo desarrollar algunos aspectos propios-un petrarquismo peruano o un barroco de Indias-, en el fondo siempre dependió de un traslado cultural bastante homogéneo, dirigido por los letrados de la monarquía.

A pesar de las diferencias que notamos en las prácticas poéticas virreinales, se las tiende a interpretar a partir de un proceso evolutivo y jerárquico, basado en la continuidad de una cultura; lo afirmaba Menéndez y Pelayo en su clásica Historia de la poesía hispanoamericana (8-10) y lo afirma todavía hoy Jorge Téllez en su reciente Poéticas del Nuevo Mundo (10). A pesar de que en los últimos treinta años se han propuesto modelos de interpretación que sobrepasan las dimensiones regionales y las dinámicas coloniales en sentido estricto (Mazzotti 9), las prácticas poéticas siguen siendo retraídas con demasiada rapidez a modelos bipolares como los de imperiocolonia o metrópolis-periferia, aun cuando esto persiga fines reivindicativos. Se olvida que durante los siglos XVI y XVII, la Monarquía católica se pensaba jurídicamente como una monarquía compuesta, cuyas élites se anexaban al centro político de diversas maneras (Elliott 7-8). Se olvida que los letrados no eran meras marionetas del poder, sino, tal vez en primera línea, transmisores y transformadores de los códigos mediante los cuales se instituía el poder (Rama 62-63).

El objetivo de este artículo es mostrar el carácter heterogéneo que la poesía adquirió en el momento de su instalación en tierras andinas y así reconocer las estelas 
que permiten la comprensión histórica de una configuración transandina en las letras virreinales que no ha sido considerada ni por las historias literarias coloniales ni las nacionales. ${ }^{1}$ A partir de dos poemas plurilingües dispuestos entre los textos preliminares de la traducción realizada por Enrique Garcés de Los sonetos y canciones del poeta Francisco Petrarcha-traducción realizada principalmente en el Perú entre 1570 y 1590 y publicada en Madrid en 1591-, me interesa analizar las tensiones que se perciben entre lo que estos poemas representan, el modo en que lo hacen, las diversas lenguas que utilizan, qué nos dice todo esto de la poesía y de un campo literario, cuyas tensiones y dinámicas superan con creces las fronteras regionales, nacionales o incluso areales; más aún, al considerar que éstos poemas abren las puertas a la primera traducción íntegra de Petrarca al castellano, ${ }^{2}$ dedicada al Rey Felipe II como muestra de las riquezas que fluyen desde el Nuevo Mundo hacia el viejo.

Estos poemas plurilingües, uno escrito por fray Miguel de Montalvo y el otro por Enrique Garcés a modo de respuesta, permiten comprender que la tradición poética virreinal en el Perú no emerge de una translatio lineal y homogénea, sino más bien de una translatio de la translatio, de un traslado de las formas, motivos, recursos y lenguas poéticas del imperio, entendidos estos como sistema transformativo y no únicamente como matriz rectora. En este sentido, la tradición y las lenguas que expresan poéticamente esta translatio están, a pesar de la jerarquización social que corresponde al contexto, en tensión plurilingüe y abiertas a los influjos de otras tradiciones y otras lenguas, a las cuales se les reconocen sus características y valores intrínsecos. En otras palabras, en el momento fundacional de la poesía en el virreinato del Perú existe ya un reconocimiento de la pluralidad de lenguas que conforman la Monarquía católica, y que éstas no necesariamente tienen que ir a dar a una supuesta cumbre lingüística, la cumbre castellana. Este reconocimiento desestabiliza el principio unívoco de la translatio imperii y revela finalmente algunas tácticas, mediante las cuales algunos poetas virreinales transformarán activamente los modos en los que se hacía y concebía la poesía en las cortes ibéricas. Esta intervención plurilingüe en la translatio no significa la

"Sobre la "configuración transandina" en cuanto modelo de lectura poético-cultural, ver Bernaschina, "Estudios transandinos". Texto que surgió a partir del panel "Estudios transandinos", organizado junto a Marco Thomas Bosshard y Ellizabeth Monasterios y presentado en el XXXIX Congreso del IILI en Cadiz.

2 Existió una traducción previa del Canzoniere realizada por el judío portugués Samul Usque [Salusque o Salomón Usque], publicada en Venecia en 1567, aunque sólo de la primera parte (Mancosu 1; Bertomeu 460). La traducción de Garcés contiene todos los poemas del cancionero, salvo cinco. Como lo aclara Luis Monguió, uno es la canción 29 "Verdi panni", que Garcés reconoce no haber podido traducir. Los otros cuatro son "los número 114, 136, 137 y 138 del canon ('De l'empia Babilonia', 'Fiamma dal ciel', 'L'avara Babilonia' y 'Fontana di dolore'), que supongo suprime por los ataques que contienen contra la Corte papal aviñonense" ("Una nota" 182).

Revista Iberoamericana, Vol. LXXXI, Núm. 253, Octubre-Diciembre 2015, 1095-1112 
inmediata aceptación de las lenguas amerindias, pero sí sienta las bases para su paulatina inclusión en los siglos a venir, como espero sugerir hacia el final de esta exposición.

Si hay que hablar de un momento fundacional de la poesía en el virreinato del Perú, es ineludible referirse a las monumentales traducciones realizadas por el arbitrista y poeta Enrique Garcés. Gracias a las labores de historiadores y críticos como Lohmann Villena, Monguió y Nuñez, entre otros, tenemos algunas noticias sobre la vida de este portugués nacido en Oporto hacia 1525, de las cuales destacan el descubrimiento de minas de mercurio en las cercanías de Huancavelica, un rol fundamental en la aplicación del "sistema de amalgamar gangas argentíferas con el mercurio para apurar la plata" (Lohmann 18) y tres grandes traducciones al castellano: la ya mencionada del Canzoniere de Francesco Petrarca, Os Lusiadas de Luís de Camões y De Regno de Francesco Patrizzi de Siena. Esta sugestiva trilogía no sólo trasladó al castellano vía el Nuevo Mundo las tres lenguas de prestigio que circulaban en ese entonces en el Imperio español -italiano, portugués y latín-, sino además conjuntó la poesía lírica de uno de los modelos más grandes para la época, la epopeya de los exploradores y los descubrimientos oceánicos, y el doctrinal del gobernante, escrito hacia fines del siglo XV por un sienés y dedicado al que fuera el aragonés Alfonso II, rey de Nápoles. Junto a estas traducciones, es también muy famosa la "Canción al Pirú" que escribiera Garcés a imitación de la "Italia mia" de Petrarca y que incluyera en su traducción, ya que en este poema aparece una de las primeras y más evidentes acusaciones políticas en forma lírica en contra de los abusos administrativos españoles y del maltrato de indios en el trabajo en las minas. ${ }^{3}$

Por mi parte, yo quiero abocarme a dos sonetos muy particulares que pertenecen a los textos preliminares de la traducción que hace Garcés de Petrarca y que corresponden a un intercambio dialógico entre el traductor y uno de aquellos amigos letrados, que forman el coro de pregoneros con el que la obra busca persuadir, mediante alabanzas e ingenios, al mecenas o sujeto del poder al cual va dedicada. Estos poemas encomiásticos, como dice Mónica Güell al revisar diversos paratextos en libros de poesía del Siglo de Oro, buscan legitimar la petición de amparo de la dedicatoria, a través de una estrategia suplementaria del poder del poeta: "el auto-elogio constituido por el mero hecho de recolectar encomios ajenos, obliga tanto más al protector, a quien se sugiere que la gloria del poeta será también la suya" (34).

Sabemos que en el caso de Garcés, la petición de amparo que acompaña sus tres traducciones dedicadas a Felipe II se enmarca en la intención del traductor por que se reconozcan sus servicios a la corona en materias de minería y difusión cultural, además de que se le devuelvan los costos de impresión de sus obras y de su estadía

\footnotetext{
La lista de estudios sobre esta canción es larga. Además de los primeros artículos al respecto de Lohmann Villena y Monguió, recomiendo la lectura de los recientes trabajos de Bermúdez Gallegos, Rose y Serna Arnaiz, todos citados en la bibliografía.
}

Revista Iberoamericana, Vol. LXXXI, Núm. 253, Octubre-Diciembre 2015, 1095-1112 
en la Península (Lohmann, "Enrique Garcés” 46-47 y Monguió, Sobre un escritor 3 y 40). Por lo mismo, sus traducciones irán encabezadas por sonetos al Rey y alabanzas del poeta mismo y de otros a sus invaluables trabajos poéticos para el Perú y para el Imperio en general. El ejemplo más explícito lo encontramos en el segundo soneto dedicatorio de la traducción de Los Lusiadas, en el cual el poeta dice directamente en el primer cuarteto: "Hauiendo la experiencia bien mostrado, / Y la que con mil lenguas lo pregona, / El augmento que a tu Real corona / Es por mi industria acumulado" (Monguió, Sobre un escritor 43).

Ahora bien, como lo dice Pedro Ruíz Pérez estudiando a Garcilaso y Góngora, las dedicatorias y textos preliminares poseen además un "valor metatextual" y un "valor metareferencial", ya que sirven "como espejos en los que el texto se mira y con los que dialoga", ofreciendo a su vez "los rasgos del código en el que [la obra literaria] funciona como tal” (50). Así, cuando Garcés encabeza el título de su traducción de Petrarca y su primer soneto con la dedicatoria a "Philippo segundo deste nombre, Monarcha primero de las Españas, e Indias Oriental y Occidental" (Petrarca fol. 3v.) no sólo realiza una doble adulación, como lo dice Monguió, al destacar que si bien Felipe era el segundo de Castilla y Aragón, era el primero de Portugal (incorporado en 1581 a sus dominios) y así el primero de todas las Españas y de todas las Indias (Sobre un escritor 3 y 6); con este juego marca también las extensiones del mundo, los diversos territorios que se conjuntan bajo su poder y la importancia que adquiere la poesía como discurso promotor de la lengua y la cultura. Como lo dice Sarmiento de Gamboa imperialmente en uno de sus poemas laudatorios a Garcés: "Diose Petrarcha a si solo al Latino / En Tusca lengua; éste en Castellano / Le diò al de Europa, al de Asia, al Africano / Y al Indio, do este frasis es contino" (Petrarca fol. 4v.).

Lentamente los poemas preliminares van dando el tono, y mediante el uso de los códigos de la época, es decir, la translatio, el tópico de las armas y las letras, la figura del Parnaso, entre otros, posicionan la traducción y la composición poética dentro de una "industria" compleja y heterogénea, que asume y reflexiona sobre las tradiciones poéticas en diversas lenguas que alimentan al castellano en su fase de expansión. Como lo demuestran los poemas plurilingües que aquí atendemos, eso sí, Garcés manifestará una visión bastante más diferenciada que la expresada por Gamboa.

El primer poema es un soneto trilingüe escrito por el Presentado dominico Fray Miguel de Montalvo, quien, según las averiguaciones que Luis Monguió logró hacer sobre él hacia 1960, se hallaba establecido entre 1548 y 1549 en el convento del Rosario de los dominicos limeños y posteriormente, en 1567, al parecer, ejerciendo el cargo de prior de la misma orden en la ciudad del Cuzco (Sobre un escritor 22). Este soneto trilingüe, compuesto casi sólo por endecasílabos heroicos con rima consonante en estructura clásica ABBAABBA CDE CDE, intercala consecutivamente versos en latín, italiano y castellano (en ese orden). El juicio de Monguió al respecto es que "dentro

Revista Iberoamericana, Vol. LXXXI, Núm. 253, Octubre-Diciembre 2015, 1095-1112 
de la inevitable desarmonía del uso de las tres lenguas, el soneto de Montalvo corre a su fin sin retrocimientos" (Sobre un escritor 25):

Henrice, gloria gentis Lusitanae, à cui le muse cosi amato hanno, que puedes compararte al Mantuano, ille Latine loquens \& tu Hispane. Per te habbiam le cithare Thoscane en elegante verso Castellano, leguntur namque, iam sermone Hispano, di Laura le belleze supra humane. Las almas que Pythagoras dezia in corpora vicissim transmigrantes in qualche modo gia ben crederemo, Viendo en ti de Petrarcha l'harmonia acumen \& leporem commorantes, $\&$ tutto quel di bon ch'in lui vedemo. (Petrarca fol. 9r.)

La traducción que Monguió ofrece en prosa es la siguiente: "Enrique, gloria de la nación lusitana, a quien las Musas han amado tanto que puedes compararte al Mantuano, hablando él latín y tú español. Gracias a ti tenemos las cítaras toscanas en elegante verso castellano y leemos ahora realmente en lengua española acerca de las bellezas sobrehumanas de Laura. Viendo en tí detenidas la armonía, la inteligencia y la gracia de Petrarca y todo lo bueno que en él vemos, bien creeremos con Pitágoras que las almas vivan transmigrantes en los cuerpos" (Sobre un escritor 56-57, n. 92).

Por su parte, la "Respuesta quadrilingüe" de Garcés, tal como lo dice el soneto mismo, intenta seguir el modelo de Montalvo - exactamente el mismo metro y la misma rima-, aunque cambia el orden de las lenguas e intercala además desde el principio versos en portugués:

Ninhum mortal ja canse nem se engane en procurar el Pindo tan lexano poi ch'in voi, sacro Mont'albo soprano, tripudiant Latiae \& Thuscae \& musae Hispanae.

Nem digão que pe longo ou breue dane

al hendecasyllabico Romano mercè dei vostri versi ch'egli fanno loquamur vt hîc etiam Lusitane. E pois lhes não falesce melodia, Y son en el dezir tan elegantes, Montalbico poema il chiamaremo.

Et sequemur hac eadem via,

Revista Iberoamericana, Vol. LXXXI, Núm. 253, Octubre-Diciembre 2015, 1095-1112 ISSN 0034-9631 (Impreso) 
Y aun puede ser seràn mejor sonantes

Che sono i Asclepiadei ch'hor noi godemo. (Petrarca fol. 9v.)

Nuevamente la traducción de Monguió: "Ningún mortal se canse ni se engañe en ir en busca del Pindo tan lejano puesto que en vos, Monte albo soberano, danzan las musas latinas, toscanas y españolas. Ni digan que pie largo o corto daña al endecasilábico romano, gracia de vuestros versos, que hacen que hablemos como él y también portugués. Y pues no les falta melodía y son en el decir tan elegantes, lo llamaremos poema montálvico. Y te seguiremos por la misma vía y aún puede ser que serán mejor sonantes que los asclepideos que ahora gozamos" (Sobre un escritor 57, n. 92).

Si en el caso del poema de Fray Miguel de Montalvo, Monguió anunciaba una inevitable desarmonía entre las tres lenguas, en el poema de Garcés ésta se hace absolutamente audible. Tras "un primer cuarteto tolerable", dice Monguió, "se enreda a partir del segundo en una prolongada imagen a base de la idea de los pies poéticos, traída a los puntos de su pluma, me imagino, por el 'tripudiant' de la metáfora inicial, por ese danzar de las Musas latinas, toscanas y españolas en el Monte-albo" (Sobre un escritor 25).

Monguió está en lo cierto. El ritmo es irregular, a veces casi un trabalenguas en su pronunciación y sería claramente un defecto, si pensamos que el objetivo aquí buscado es una composición poética que ha de ser transparente: un artificio verbal que aprovechando acaso una matriz rítmica común, nos haga olvidar que el soneto está escrito, por voluntad del poeta -o más bien por un modo determinado de enfrentar y expresar sus circunstancias-, en tres o cuatro lenguas encadenadas.

Aquí tal vez no esté demás recordar que estos poemas plurilingües, en tanto ingeniosos juegos o divertimentos verbales, cuentan con una larguísima tradición que es necesario diferenciar para comprender finalmente qué es lo que hacen los poemas de Montalvo y Garcés instalados en los preliminares de esta traducción de Petrarca. Como nos lo recuerdan Rafael de Cózar y Antonio Alías, ya Tertuliano y Ausonio, en los siglos II y IV, por aludir ejemplos de renombre, habían compuesto poemas - epigramas y centones - intercalando versos griegos y latinos (Cózar I: 267 y Alías s.p.). En el ámbito romance, como lo destaca Monguió, existen poemas plurilingües “desde el antiquísimo famoso diálogo del trovador Raimbaud de Vaqueiras con su genovesa, en el que alterna el provenzal y genovés estrofa a estrofa" (Sobre un escritor 25). En el Siglo de Oro tampoco faltan ejemplos de diversa índole: muy frecuente es la incorporación de un verso extranjero en el poema, generalmente una cita, como sucede en el Soneto XXII de Garcilaso, en el que el último terceto se concluye con un verso de Petrarca (Monguió, Sobre un escritor 25; Cardona 345). Ejemplos más radicales son el soneto cuatrilingüe de Góngora "Las tablas del bajel despedazadas", fechado hacia 1600 y escrito en castellano, latín, toscano y portugués, y el centón cuatrilingüe en forma de soneto que compuso Lope de Vega a partir de la combinación de versos de Ariosto,

Revista Iberoamericana, Vol. LXXXI, Núm. 253, Octubre-Diciembre 2015, 1095-1112 
Camões, Petrarca, Tasso, Horacio, Serafino, Boscán y Garcilaso -con predominancia de Petrarca y Horacio: tres versos para cada uno (Charlo Brea 150-51 y Alías s. p.).

Sea por el lado de una poesía ingeniosa o por el de una poesía cortesana de corte más serio, en estos casos hay que tener en cuenta que la utilización explícita de una o más citas refleja una práctica intertextual que marca una filiación, apropiación e incluso control de los estilos o de las figuras poéticas convocadas. El soneto de Lope, llevado conscientemente al punto del pastiche, propone en primera instancia un canon de antiguos y modernos; una conjunción de grandes maestros, que podría interpretarse como una venia del poeta a las fuentes de las que bebe:

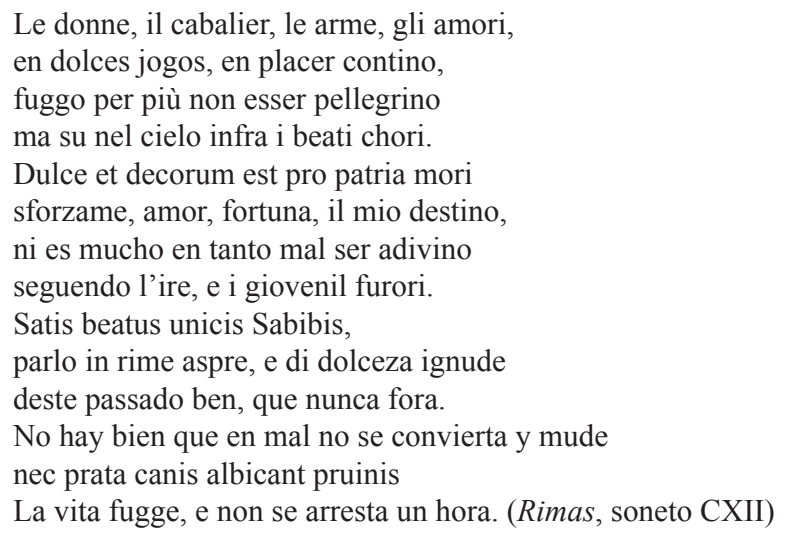

A primera vista pareciera levantarse aquí una senda alabanza, no obstante, al observar el tema que construyen los versos seccionados - la huida del poeta de los temas peregrinos de la poesía cortesana ante el inevitable paso del tiempo-y al notar que, en el fondo, la voz poética no es más que el resultado de una labor técnica de recorte y selección, vemos que la disposición de aquellos versos, se convierte más bien en un museo inmóvil o en un monumento funerario "deste pasado ben, que nunca fora". Con claridad, el último terceto desecha estos "juveniles furores", y lo hace además, con la misma voz de estos poetas: "No hay bien que en mal no se convierta y mude / nec prata canis albicant pruinis / La vita fugge, e non se arresta un hora".

Esta utilización negativa de los versos plurilingües adoptados de la tradición por Lope de Vega, adquiere otra dimensión si los observamos a la luz del Soneto XXII de Garcilaso. Este caso es llamativo, no sólo por el uso paródico que puede insinuar la utilización de un verso de Petrarca al final del soneto, como lo dice Ignacio Navarrete en Orphans of Petrarch (230), sino además por los comentarios que provoca esta práctica en las Anotaciones de Fernando de Herrera. Aunque lo hayan hecho de muy buena manera Petrarca, Marcial y Ausonio, entre otros, dice Herrera, "pareceme que

Revista Iberoamericana, Vol. LXXXI, Núm. 253, Octubre-Diciembre 2015, $1095-1112$ 
se puede dezir por los que hazen esto lo que se dixo por los que escrevian junto verso i prosa; que eran dos vezes sin juizio, porque es mescla mal considerada i agena de la prudencia i decoro poetico, i grandemente huida i abominada de todos" (Herrera 173).

La importancia del juicio para sostener la prudencia y el decoro en la expresión, remite evidentemente al modelo cortesano expuesto en tratados como Il Cortegiano de Baldassare Castiglione o La Civil Conversatione de Stefano Guazzo, aunque con aún más claridad a la apropiación de este modelo por la corte hispana. Un modelo que, como se aprecia en el Dialogo de la lengua de Juan de Valdés, hace énfasis en la práctica social de la corte y en los usos de la lengua, y que oponiéndose a preceptos y "gramatiquerías" (40), propone fuentes y características propias para el cortesano español -el cuidado en vez de la sprezzatura y, por supuesto, el castellano en vez de la lengua toscana. Como lo explica Navarrete en otro artículo, el estilo cortesano que promueve Juan de Valdés se fundamenta en un estilo oral, claro, decoroso y breve, y por lo tanto, su correspondiente poético debe evitar latinazgos, retruécanos y todas aquellas licencias que Juan del Encina en el siglo XV defendía como la especial provincia de los poetas ("Juan de Valdés" 10). A partir de esta propuesta, centrada indirectamente en Garcilaso y cultivada posteriormente por Fernando de Herrera y Diego Hurtado de Mendoza, entre otros, Navarrete arguye que, en la segunda mitad del siglo XVI, se conformó un estilo poético imperial, que apropiándose de las formas latinas e italianas, apostaban por una expresión concisa, un estilo 1lano, en el que los sentimientos aparecen siempre mediados por la forma y por un distanciamiento del sujeto hablante del peligroso objeto de su deseo ("Juan de Valdés" 22).

Que el sujeto poético de Fernando de Herrera se constituya siempre con estas características es una afirmación que es necesario relativizar, como lo expone claramente Ricardo Padrón en su ensayo "Exile and Empire". No obstante, lo que sí ha quedado largamente probado por varios críticos literarios, es el hecho que en sus Anotaciones a Garcilaso, Herrera expone con toda claridad cómo su poesía y, más aún, su modelo de exégesis literaria, están profundamente influidos por una perspectiva imperial.

En el modo en que Herrera interviene explicativa y valorativamente los poemas de Garcilaso, se aprecia que la reinterpretación que hace de la poesía de aquel es tanto un abrirse campo dentro del canon poético peninsular, como una transformación de "el príncipe de los poetas castellanos" en un antecedente de su estilo poético y no al revés. De tal forma, mediante una metafórica heroica y guerrera, Herrera hace del melancólico y doliente Garcilaso un ejemplo de los poetas que se lanzan a la conquista de la poesía, tal como los exploradores en pos de la conquista del Nuevo Mundo (Randel 473).

Además, como queda plasmado en las primeras líneas del prólogo que hace "El Maestro Francisco de Medina a los lectores", el libro completo se considera como una de las armas principales de la expansión imperial: "siempre fue natural pretension de las gentes victoriosas, procurar estender no menos el uso de sus lenguas, que los

Revista Iberoamericana, Vol. LXXXI, Núm. 253, Octubre-Diciembre 2015, $1095-1112$ 
términos de sus imperios" (Herrera 1). Por lo mismo, todo rasgo extranjerizante, toda debilidad sentimental y afeminamiento italianos (así son los juicios herrerianos) no pueden aparecer dentro de la poesía castellana, a menos que lo hagan a modo de botín de guerra (Schmidt 13-17 y Padrón 503). Y si han de aparecer otras fuentes y otros estilos poéticos, entonces que sean aquellos de la antigüedad (Padrón 504), aquellos extranjeros familiares que constituyen el lejano fundamento de la genealogía del imperio (Asensio 407 y MacCormack 10-12). En otras palabras, lo que aquí se percibe es la estructuración de una tradición poética que si bien participa evolutivamente del latín y acaso de otras lenguas romances, lo que hace principalmente es superarlas, relegarlas al pasado patrimonial.

Es muy probable que sea esta misma idea la que opera detrás del Arte poética española (Salamanca 1592) del jesuita Juan Díaz Rengifo, al establecer los preceptos para componer lo que él denomina el soneto en dos lenguas y que, como lo señala Albert Rossich, más que un poema bilingüe es un texto de doble lectura (Rossich 501). Díaz Rengifo dice al respecto:

Puedense tambien hazer Sonetos en dos lenguas, o componiendo parte de los versos en una, y parte en otra, o (lo que es más difficultoso) componiendolos de tales dictiones que juntamente pertenezcan a ambas lenguas. [...] Bien es verdad, que la escritura de la una, y de la otra lengua, son differentes: pero basta que sea una, o quasi una la pronunciacion. (56-57)

O sea, habla de la posibilidad de alternar lenguas diferentes, sin embargo desestima su valor, ya que no representan un verdadero desafío para el ingenio. Al menos no ante la otra posibilidad que él ofrece y en la que, según él, latín y castellano son simultáneamente inteligibles. Cito aquí el primer cuarteto del ejemplo que él mismo expone, para dar una idea más concreta de lo que se entiende bajo este tipo de composición: "Miscera Francia, que sustentas gentes / Apóstatas, heréticas, viciosas, / Que machinando fraudes cautelosas, / Perturban infinitos inocentes: [...]" (57).

Lo que Díaz Rengifo propone parece un entretenido ejercicio del ingenio-similar a la composición de palíndromos-en el cual el poeta debe entregarse no tanto a la industria sino más bien al trabajo, como lo advertirá un par de años más tarde Luis Alfonso de Carvallo en Cisne de Apolo, de buscar justamente aquellas palabras derivadas del latín y que aún conservan algo de su significado, para disponerlas después de manera relativamente coherente (238). No obstante, este divertimento revela además una clara manifestación de la ideología imperial.

En su desarrollo temprano, este ejercicio se ancla en las disputas que surgen entre los siglos XV y XVI entre las distintas lenguas romances por demostrar cuál de ellas es la más cercana al latín y con ello, probar su jerarquía sobre las otras (Rossich 502 y Cardona 346). Así, este modo de componer sonetos principalmente en dos lenguas

Revista Iberoamericana, Vol. LXXXI, Núm. 253, Octubre-Diciembre 2015, 1095-1112 
-aunque posteriormente se encontrarán también ejemplos que dicen ofrecer lecturas en latín, castellano y catalán (Rossich 505)- postula siempre una matriz lingüística hegemónica -el latín, en este caso-y obliga a las demás lenguas con las que se combina a subsumirse a sus leyes, a desprenderse de sus palabras de uso cotidiano, a sus características dialectales, a las influencias de otras lenguas (en el caso del castellano de los Siglos de Oro, pensemos sólo en las palabras de proveniencia árabe; en el caso de nuestras variantes latinoamericanas actuales, pensemos además en las palabras de origen quechua, aimara, mapuche, entre tantas otras).

En definitiva, este juego del ingenio poético tiene como objetivo último crear la ilusión de un traspaso inmediato y transparente entre aquella lengua hegemónica que rige la matriz del poema y su manifestación vulgar o minoritaria; y con minoritaria no hablo de cantidad, sino de la calidad impuesta a ella desde la lengua hegemónica. Y puede parecer un juego, pero "afán caduco y, bien mirado", este es el mismo procedimiento con el que se enjuiciará en los siglos XV y XVI la calidad del quechua y con el que se elaborarán sus primeras gramáticas (MacCormack 177ss.).

Ante este panorama, el intercambio poético tri- y cuatrilingüe entre fray Miguel de Montalvo y Enrique Garcés en los preliminares de la primera traducción completa al castellano del Canzoniere cobra una dimensión que a primera vista no tenía. Estos poemas no son sólo una forma más de hacer "composturas en dos lenguas", como lo insinúa Carvallo en el Cisne de Apolo al mencionar como ejemplos de estos poemas que intercalan versos de distintas lenguas a fray Montalvo y Garcés (239), sino un tipo de composición que abre una reflexión poética y crítica sobre el cultivo de las lenguas dentro de la Monarquía católica.

Regresemos sobre los preliminares: antes de los sonetos plurilingües, el intercambio poético entre fray Montalvo y Garcés se inicia con dos sonetos en castellano en los que, como de costumbre, se utilizan figuras provenientes del Parnaso para alabar los dotes poéticos de cada uno de los interlocutores. Así, fray Montalvo celebra con agudeza filosófica las virtudes de la traducción de Garcés y cómo ésta encarna una translatio efectiva del Parnaso toscano al español. Dice en el soneto, que el alma de Petrarca en la "suprema hierarchia", experimenta "accidental contento" al ver como "tan auisada y sabiamente / en Español idioma su Thalia / no menos qu'en Thoscano ser solia" (Petrarca fol. 8v.). Por su parte, Garcés -agudo lector- celebra la sabiduría de su interlocutor y jugando con su apellido, es decir Montalvo/Monte-albo, señala al soneto de aquel, y por metonimia a su autor, como el verdadero Parnaso del cual el traductor no deja de aprender: "Si creer se pudiesse humanamente / aquello que del Pegaso dezia / la fabulosa Grecia, yo diria / que ese es el monte à do cauò la fuente" (Petrarca fol. 8v. y 9r.).

El tema se continúa y profundiza en los sonetos plurilingües: de un lado, la alabanza de una translatio completa (en el doble sentido de la palabra) mediante las industrias

Revista Iberoamericana, Vol. LXXXI, Núm. 253, Octubre-Diciembre 2015, $1095-1112$ 
de Garcés, y del otro, la posibilidad de que el Parnaso se afinque en tierras peruanas. Como se aprecia en el soneto trilingüe, fray Montalvo alaba a Garcés a través de su traducción. Reconociendo su origen lusitano, lo nombra igualmente Virgilio español, gracias a quien ahora contamos con la música toscana y la belleza de Laura en verso castellano. Pero eso no es todo: viendo que en Garcés están detenidas la armonía, la inteligencia y la gracia de Petrarca, dice que bien puede creerse ya en la transmigración de las almas, implicando con eso que el alma de Petrarca ha transmigrado a Garcés. Este recurso a la transmigración es decisivo. Con él se estructura todo el sentido del poema, tanto a nivel de la forma como del contenido.

Como lo comentamos más arriba, el soneto se compone en endecasílabos y sigue el modelo clásico de rima consonante ABBAABBACDECDE.Además, en su acentuación, el poema evidencia un esfuerzo por construir entre sus versos un ritmo estable y una cierta melodía para que las diversas lenguas que lo componen establezcan una unidad. Unidad que se refleja también en el encadenamiento ordenado de las lenguas -latín, toscano y castellano- y que encuentra su correlato externo en la evolución lingüística de las lenguas vulgares a partir del latín. Es decir, en la translatio imperii de Nebrija y en su "concepción de la lengua como criatura orgánica, ligada a la vida y muerte de los imperios" (Asensio 406).

Desde el contenido, esta unidad se justifica además conceptualmente por la idea neoplatónica de la armonía de las esferas, de las cuales las tres lenguas logran participar a través de la poesía, que en el mundo se ha transmitido en una clara genealogía: el Mantuano (Virgilio) -Petrarca- Garcés. De este modo, por mucho que la idea de la transmigración de las almas en el poema sugiera la existencia de una participación total de las tres figuras de un entendimiento superior en las esferas eternas mediante la poesía, también lo que hace es reforzar implícitamente que en el mundo terrenal la manifestación de dicho saber está atada a la sucesión temporal de los imperios y de sus propias lenguas. En otras palabras: a pesar de que las ideas existan en una eterna "suprema hierarchia", como lo decía Montalvo en el primer soneto, y que las traducciones de Garcés nos permitan leer "di Laura le belleze supra humane", como dice en el segundo, en nuestro mundo, la transmigración de la sabiduría sólo puede experimentarse secuencialmente. Lo que el poema del dominico nos dice es que el lusitano Garcés, comprendiendo este desarrollo orgánico, ha abandonado su lengua materna para contribuir en la translatio imperii, haciendo con Petrarca lo que éste hizo con Virgilio y llevando los studia humanitatis hacia los confines del imperio.

Dado este modelo, la inclusión de Garcés de versos en portugués es de una significación verdaderamente colosal. Ya sólo en lo que refiere a la forma es una transgresión de las reglas que rigen a los sonetos de respuesta, que deben ceñirse estrictamente al modelo ofrecido por el primero. Garcés conocía estas reglas, como lo demuestra en la traducción de intercambios similares de Petrarca con otros poetas

Revista Iberoamericana, Vol. LXXXI, Núm. 253, Octubre-Diciembre 2015, 1095-1112 
italianos (Monguió, "Una nota" 180) y en el respeto de la medida y rima de los versos de Montalvo; sin embargo, al inicio del soneto introduce un verso en portugués e invierte la secuencia de las lenguas -portugués, castellano, toscano y latín-, dejándola correr hasta que al final la rompe rematando los dos últimos versos con uno en castellano y el último en toscano.

Si seguimos a Monguió, la primera impresión que provoca este cambio es desarmonía y enredo; tal vez, como lo citamos más arriba, por la prolongación de la imagen de los pies poéticos, convocada en el poema por el "tripudiant", por la danza de las Musas latinas, toscanas y españolas en el Monte-albo. De hecho, al concluir el segundo cuarteto y explicarse en el soneto la presencia de las cuatro lenguas, se produce un encabalgamiento poco feliz en contraste con las demás pausas versales: "mercè dei vostri versi ch'egli fanno / loquamur vt hîc etiam Lusitane". No obstante, a la luz de los debates poéticos sobre el uso de diversas lenguas y el modo en cómo éstas han de confluir en el castellano, esta arritmia del "como aquí también portugués" es un llamado de atención sobre la forma del poema y de lo que su contenido expresa en contraste con el soneto de Montalvo.

El soneto de Garcés ofrece en el primer cuarteto una imagen con la que da por hecho el traslado del Parnaso al Perú. Fundamental es que no lo sitúa en la traducción de Petrarca o en los diversos poemas preliminares, sino en la práctica o doctrina poética de fray Montalvo, en la que simultáneamente "tripudiant Latiae \& Thuscae \& musae Hispanae". Ese baile, como lo indica el desarrollo del resto del soneto, posee diversos ritmos y diversas hablas, que en su conjunto han dado forma a un nuevo poema, acaso una nueva forma de metrificar: el poema montálvico. Ahora bien, a diferencia del principio estructurante que ofrecía el soneto del dominico mediante la transmigración, el soneto del portugués propone la figura de un nuevo Parnaso. No un Parnaso español, que intenta asimilar o sobreponerse a los distintos Parnasos precedentes (Vélez-Saínz 20-22), sino un Parnaso del Nuevo Mundo, configurado en la simultaneidad de las tradiciones que lo animan. Una simultaneidad que no implica homogeneidad, sino que en sus arritmias destaca precisamente la diferencia.

El endecasílabo romano no se daña con la intromisión de otros ritmos, dice Garcés en el primer terceto, no carece de melodía y adquiere, en su decir, aquella elegancia que le otorgan cada una de las lenguas que lo conforman. La alusión al decoro propio de las lenguas, me parece, es una apropiación del ideal que Juan de Valdés defendía para el uso del castellano en la corte: hablo como escribo y escribo como hablo (74). Claro que en Juan de Valdés, quien en su diálogo instruía a curiosos napolitanos sobre las virtudes del castellano, el dictum implicaba primero una observación cuidadosa de los comportamientos lingüísticos de la corte castellana en tanto modelo y luego su traspaso a la escritura y no al revés (99).

En el caso de Garcés pasa algo distinto, puesto que si a él o a otros se les da el hablar en varias lenguas, entonces es lógico que escribirá como habla y hablará como escribe.

Revista Iberoamericana, Vol. LXXXI, Núm. 253, Octubre-Diciembre 2015, 1095-1112 
Se aprecia aquí un giro en el ideal poético, acaso también en el cortesano, sobre todo si pensamos en la fuerte presencia que al parecer tenían el toscano y el portugués en el virreinato peruano. Como lo demuestra Alicia de Colombí-Monguió, Diego Dávalos y Figueroa da claras señas de que el toscano era lengua de uso frecuente en la corte o al menos en las reuniones de letrados. En su Miscelanea Austral de 1602 dice al respecto:

...algunos que la professan quieren que se hable como la española, en lo que no creo aciertan, aunque alegan ser assí más fácil de parlar y que se dexa mejor de entender. Otros dizen que a de ser como los mesmos toscanos la hablan, pues siendo assí (hablada a la española) no es lengua toscana ni española, sino confusión, y éstos me parece que dizen mejor. (citado por Colombí 191)

Diego Mexía de Fernangil, por su parte, para dar más prestigio a la heroica dama que escribió el "Discurso en loor de la poesía" que encabeza su Primera parte del Parnaso Antártico, menciona lo muy versada que ésta era en lengua toscana y portuguesa.

Estos enunciados dejan entrever un ideal poético que surge en el virreinato del Perú y que en el soneto manifiesta afinidad y respeto a la capacidad expresiva de cada una de las lenguas romances de prestigio y cuyo uso, sea cada una por separado o conjuntamente, puede llegar a ser más sonoro y más natural que la imposición de un férreo modelo afincado en la imitación o traducción de la antigüedad: "Y puede ser serán mejor sonantes", dice Garcés en los últimos dos versos, "che sono i Asclepiadei ch'hor noi godemo".

El asclepiadeo, hay que aclarar, es un verso que por iniciarse con tres sílabas largas difícilmente puede ser traspuesto con naturalidad a las lenguas romances. Si eso no basta para comprender el juego con el que concluye Garcés, recordaremos además, que el asclepiadeo es la forma versal que Horacio reservó para los poemas que enmarcan sus tres libros de las Odas (Kytzler 118). En la primera, la oda I, 1, Horacio enaltece la figura de Mecenas, con la que él mismo se compara, al narrar su vida, sus esfuerzos y el valor que le ha otorgado la poesía. En la última, la oda III, 30, Horacio declara haber levantado con su obra un monumento imperecedero, que le granjeará la fama y la gloria eternas a él y a su mecenas. En ambas odas tratará, además, temas fundamentales sobre el arte poética (Kytzler 80-81).

Concluyo: Si Garcés se decide a dar sus traducciones a la imprenta y dedicarlas elogiosamente a Felipe II, dejando quizás una sensación servil, esto responde, por una parte, a la innegable realidad de la Monarquía Católica y su proyecto expansionista y evangelizador, y por la otra, al funcionamiento del mecenazgo durante los Siglos de Oro (ver Vélez-Sainz; Güell 34). No hay que olvidar que Garcés utiliza las dedicatorias y algunos poemas preliminares de sus traducciones a modo de memoriales, para demandar una retribución monetaria tanto por sus servicios materiales como espirituales para la Monarquía en el Nuevo Mundo.

Revista Iberoamericana, Vol. LXXXI, Núm. 253, Octubre-Diciembre 2015, 1095-1112 
Ahora bien, si por una parte, podríamos creer que el trabajo de Garcés de traducir tres grandes libros - diferentes géneros literarios vinculados a tres lenguas de importancia- forma parte de un proceso de conducción y reducción de la tradición romance al castellano, el gesto de sus poemas preliminares invita al desengaño. Como intenté mostrarlo aquí, varios de los sonetos que compone Garcés junto a o en contraste con aquellos aportados por su coro de pregoneros, constituyen un guiño al lector, que informa sobre las complejidades del proceso de la translatio y abren camino a otras posibles lecturas.

No quiero decir que en esta poesía no esté funcionando todo un sistema cortesano y literario con sus leyes y jerarquías lingüísticas y literarias, sino que quiero decir precisamente eso, porque sólo así se aprecia la manera en que no la lengua del imperio, sino las lenguas del Imperio y sus formas poéticas llegaron al virreinato y se transformaron en el Nuevo Mundo. El modo en que Garcés alude a la figura del Parnaso, como un monte en el que bailan simultáneamente musas latinas, toscanas, castellanas y “aquí también” portuguesas, nos revela mucho de la imagen poética que se tiene del mundo desde el virreinato, a la vez que tensiona la genealogía jerárquica con la que se percibía y hasta ahora hemos percibido la translatio de las musas. La exposición de las diversas lenguas en sus diferencias acentúa la mediatez de la traducción y figuradamente constituye un Parnaso en el que las tradiciones poéticas interactúan y se influyen las unas a las otras. Atender a las tensiones que surgen de estos sonetos plurilingües -tensiones entre las lenguas utilizadas, tensiones entre los modelos de lectura de ambos sonetos, tensiones entre las tradiciones que convocan y cómo las articulan en continuidades secuenciales o simultaneidades discontinuashacen posible observar con mayor precisión los modos en que se construyó una tradición poética en el Perú virreinal; tradición a la que no es posible hacer justicia, si la incluimos sin diferenciaciones en un modelo colonial o en un proceso histórico que necesariamente desembocará en las literaturas nacionales. Una mirada al pasado de esta índole, pensando en lo que hoy podríamos llamar configuraciones transandinas, implica comprender que desde el momento de la instalación del virreinato, se producen movimientos y transformaciones culturales de suyo heterogéneos y que complejizan aún más la constitución de tradiciones literarias y culturales. Una mirada así, implica además, reconocer una mayor agencia de los actores culturales y literarios, quienes de la mano de la poesía se atrevían a transformar, desde su posición en el Nuevo Mundo, la forma en que recibían las tradiciones poéticas heredadas por la historia o desde las cortes europeas.

De este modo, en lo que respecta a la clásica idea de un castellano imperial que se impuso homogéneamente a todos los letrados virreinales, si nos fijamos en las rutas y contactos literarios que trazan los textos preliminares de las obras virreinales peruanas, se nos harán visibles configuraciones y modos de lectura en tensión plurilingüe que hasta ahora han pasado desapercibidos. Por ejemplo, a través de Diego de Aguilar,

Revista Iberoamericana, Vol. LXXXI, Núm. 253, Octubre-Diciembre 2015, 1095-1112 
quien también escribe un soneto en alabanza a Garcés en la traducción de Los Lusiadas, llegaremos a su Marañon y a los sonetos en francés, toscano y castellano que compone Carlos de Maluenda en su alabanza (Aguilar 156-57 y 420). Hay algo más en el cultivo de estos sonetos en diversas lenguas que la mera fanfarronería de un dominio idiomático plural; está la existencia de distintas tradiciones poéticas que son convocadas con ese gesto, está la sensación de que en una lengua se dice algo de un modo que en la otra requiere de expresiones diferentes, está la tensión de una simultaneidad que tal vez en la corte ibérica no fuera posible de hacer presente si no era ya mediante una jerarquización determinada. Con esa simultaneidad de textos y de lenguas, acaso logremos ver también con más claridad el guiño del Inca Garcilaso, quien en la primera parte de los Comentarios reales intervenía las traducciones latinas que Blas Valera había hecho de canciones quechuas, proponiendo a su lado versiones y comentarios en castellano, que nos decían que lo que decía Valera, se decía de otra manera, aunque con igual elegancia, en castellano y en quechua.

\section{BiBLIOGRAFÍA}

Aguilar y Córdoba, Diego de. El Marañon. Estudio, edición y notas de Julián Díez Torres. Madrid/Frankfurt a. M.: Iberoamericana/Vervuert, 2010.

Alías Bergel, Antonio J. "Camões laureado: Legitimación y uso poético de Camões durante el bilingüismo ibérico en el "período filipino"”. Espéculo. Revista de estudios literarios 42 (2009): s.p.

Asensio, Eugenio. "La lengua compañera del imperio: Historia de una idea de Nebrija en España y Portugal”. Revista de filología española 43 (1960): 399-413.

Bertomeu Masiá, María José. “Los sonetos y canciones del poeta Francisco Petrarcha de Enrique Garcés. Notas sobre el Canzoniere de Francesco Petrarca en la América del S. XVI". Revista de Literatura 69/138 (2007): 449-65.

Bermúdez Gallegos, Marta. "Diálogos entre texto y contexto: la poesía de Enrique Garcés y sus cartas al Virrey". Crítica y descolonización: el sujeto colonial en la cultura latinoamericana. Beatriz González Stephan y Lucía Helena Costigan, eds. Caracas: Universidad Simón Bolívar/Ohio State University, 1992. 333-52.

Bernaschina Schürmann, Vicente. "Estudios transandinos: propuestas para viejos y nuevos diálogos poético-críticos". Diálogos culturales en la literatura iberoamericana. Actas del XXXIX Congreso del Instituto Internacional de Literatura Latinoamericana. Consuelo Reverte Bernal, ed. Madrid: Verbum, 2013. 1630-1641. Cardona, Ángeles. "El soneto trilingüe de Juan de Ovando y Santarén". Actas del IV Congreso Internacional de la Asociación Internacional Siglo de Oro (AISO). Tomo I. María Cruz García de Enterría y Alicia Cordón Mesa, eds. Alcalá de Henares: Universidad de Alcalá, 1998. 341-52.

Revista Iberoamericana, Vol. LXXXI, Núm. 253, Octubre-Diciembre 2015, 1095-1112 
Carvallo, Luis Alfonso de. Cisne de Apolo. Introducción, edición y notas de Alberto Porqueras Mayo. Kassel: Edition Reichenberger, 1997.

Charlo Brea, Luis: "Una composición bilingüe del siglo XVII". Excerpta Philologica 3 (1993): 149-198.

Colombí-Monguió, Alicia de. Entre voces y ecos: de poética renacentista y poesía hispánica. México: Universidad Nacional Autónoma de México, 2011.

Cózar, Rafael de. "Fundamentos históricos de la experimentación poética española".

2 Tomos. Tesis Doctoral. Universidad de Sevilla, 1984.

Díaz Rengifo, Juan. Arte poética española. Salamanca: Miguel Serrano de Vargas, 1592.

Elliott, John H. "A Europe of Composite Monarchies". Spain, Europe and the Wider World: 1500-1800. New Haven: Yale UP, 2009. 3-24.

Güell, Mónica. "Paratextos de algunos libros de poesía del Siglo de Oro. Estrategias de escritura y poder". Paratextos en la literatura española (Siglos XV-XVIII). Soledad Arredondo Sirodey; Pierre Civil y Michel Moner, comps. Madrid: Casa de Velázquez, 2009. 19-36.

Herrera, Fernando de / Garcilaso de la Vega. Obras de Garci Lasso de la Vega con anotaciones de Fernando de Herrera. Sevilla: Alonso de la Barrera, 1580.

Kytzler, Bernhard. Horaz: Eine Einführung. Stuttgart: Philipp Reclam, 1996.

Lohmann Villena, Guillermo. "Un pasquín contra el Virrey Don Francisco de Toledo". Revista de Indias 23 (1946): 111-13.

"Enrique Garcés, descubridor del mercurio en el Perú, poeta y arbitrista". STVDIA 27-28 (1969): 7-62.

MacCormack, Sabine. On the Wings of Time: Rome, the Incas, Spain, and Peru. Princeton: Princeton UP, 2007.

Mancosu, Paola. "El Cancionero de F. Petrarca, en la versión de Enrique Garcés (1591)". Cervantes Virtual. Alicante: Biblioteca Virtual Miguel de Cervantes. 2012. <http://www.cervantesvirtual.com/obra/el-cancionero-de-f-petrarca-en-laversion-de-enrique-garces-1591/>. 13 sept. 2012.

Mazzotti, José Antonio. "Las agencias criollas y la ambigüedad 'colonial' de las letras hispanoamericanas". Agencias criollas: La ambigüedad "colonial” en las letras hispanoamericanas. José Antonio Mazzoti, ed. Pittsburgh: Instituto Internacional de Literatura Iberoamericana, 2000. 7-35.

Menédez y Pelayo, Marcelino. Historia de la poesía hispanoamericana. Tomo I. (Vol. 27 de las Obras completas) Madrid: Consejo Superior de Investigaciones Científicas, 1948.

Mexía de Fernangil, Diego. Primera parte del Parnaso Antártico de Obras Amatorias. Edición facsimilar e introducción de Trinidad Barrera. Roma: Bulzoni Editore, 1990. Monguió, Luis. Sobre un escritor elogiado por Cervantes. Los versos del perulero Enrique Garcés y sus amigos (1591). University of California Publications in Modern Philology, Volume 58, No. 1. Berkeley \& Los Angeles: U of California P, 1960.

Revista Iberoamericana, Vol. LXXXI, Núm. 253, Octubre-Diciembre 2015, 1095-1112 
"Una nota sobre Petrarquismo en el Perú del siglo XVI". Influencias extranjeras en la literatura iberoamericana y otros temas. Memoria del noveno congreso del instituto internacional de literatura iberoamericana (31 de agosto, 1 y 2 de septiembre 1959). México: s. e., 1962. 175-88.

Navarrrete, Ignacio. "Juan de Valdés, Diego Hurtado de Mendoza, and the Imperial Style in Spanish Poetry". Renaissance and Reformation / Renaissance et Réforme 28/3 (2004): 3-25.

Orphans of Petrarch: Poetry and Theory in the Spanish Renaissance. Berkeley: U of California P, 1994.

Nuñez, Estuardo. "El primer traductor de Petrarca y Camoens en América”. Cuadernos Americanos 102/1 (1959): 234-42.

Padrón, Ricardo. "Exile and Empire: The Spaces of the Subject in Fernando de Herrera". Hispanic Review 70/4 (2002): 497-520.

Petrarca, Francesco. Los sonetos y las canciones del poeta Francisco Petrarcha, que traduzia Henrique Garces de la lengua Thoscana en Castellana. Dirigido a Phillipo Segundo deste nombre, Monarcha primero de las Españas, è Indias Oriental. Madrid: Guillermo Droy, 1591.

Rama, Ángel. La ciudad letrada. 1984. Prólogo de Carlos Monsiváis. Santiago: Tajamar Editores, 2004.

Randel, Mary Gaylord. "El lenguaje de la conquista y la conquista del lenguaje en las poéticas españolas del Siglo de Oro". Actas del IX Congreso de la Asociación Internacional de Hispanistas. Tomo I. Sebastian Neumeister, ed. Frankfurt a. M.: Vervuert, 1989. 469-75.

Rose, Sonia V. "Petrarca en los Andes: la 'Canción al Perú' de Enrique Garcés". Máscaras, tretas y rodeos del discurso colonial en los Andes. Bernard Lavallé, ed. Lima: Instituto Francés de Estudios Andinos y Pontificia Universidad Católica del Perú, Instituto Riva-Agüero, 2005. 85-119.

Rossich, Albert. "Formas del plurilingüismo literario: textos de doble y triple lectura". Studia aurea: Actas del III Congreso de la Asociación Internacional Siglo de Oro (AISO). Tomo I. Pamplona/Toulouse: GRISO-LEMSO, 1996. 501-12.

Ruiz Pérez, Pedro. "Garcilaso y Góngora. Las dedicatorias insertas y las puertas del texto". Paratextos en la literatura española (siglos XV-XVIII). Soledad Arredondo Sirodey; Pierre Civil y Michel Moner, comps. Madrid: Casa de Velázquez, 2009. 49-70.

Téllez, Jorge. Poéticas del Nuevo Mundo: articulación del pensamiento poético en América colonial (siglos XVI, XVII y XVIII). México D. F.: Siglo XXI, 2012.

Schmidt, Rachel. "Herrera's Concept of Imitation as the Taking of Italian Spoils" Caliope 1/1-2 (1996): 12-26.

Serna Arnaiz, Mercedes. 'La poesía de carácter 'reivindicativo' en el Perú colonial: siglos XVI y XVII’. Revista electrónica de estudios filológicos 15 (2008): 1-13.

Revista Iberoamericana, Vol. LXXXI, Núm. 253, Octubre-Diciembre 2015, 1095-1112 
Valdés, Juan de. Diálogo de la lengua. Edición, introducción y notas de José F. Montesinos. Madrid: Espasa-Calpe, 1976.

Vega, Lope de. Rimas. Ramón García González, ed. Alicante: Biblioteca Virtual Miguel de Cervantes, 2003. <http://bib.cervantesvirtual.com/servlet/ SirveObras/05814963289458462977857/index.htm>. 20 nov. 2013.

Vélez-Sainz, Julio. El Parnaso español: Canon, mecenazgo y propaganda en la poesía del Siglo de Oro. Madrid: Visor Libros, 2006. 